\title{
Maternal Cosmetics and the Risk of Autism: A Case-Control Pilot Study
}

\author{
Hassan Mohamed Elnady¹, Abdelrahim Abdrabou Sadek2, Hanan Yousif Aly³, \\ Wafaa M. Abdelmagid", Rania A. Radwan'5, Amr Ahmed Othman² \\ ${ }^{1}$ Department of Neurology, Sohag University, Sohag, Egypt \\ ${ }^{2}$ Department of Pediatric Neurology, Sohag University, Sohag, Egypt \\ ${ }^{3}$ Department of Psychiatry, Sohag University, Sohag, Egypt \\ ${ }^{4}$ Department of Dermatology and Venereal Diseases, Sohag University, Sohag, Egypt \\ ${ }^{5}$ Department of Forensic Medicine and Clinical Toxicology, Sohag University, Sohag, Egypt \\ Email: hass_elnady@yahoo.com
}

How to cite this paper: Elnady, H.M. Sadek, A.A., Aly, H.Y., Abdelmagid, W.M., Radwan, R.A. and Othman, A.A. (2020) Maternal Cosmetics and the Risk of Autism: A Case-Control Pilot Study. Journal of Behavioral and Brain Science, 10, 105-117. https://doi.org/10.4236/jbbs.2020.102006

Received: December 7, 2019

Accepted: February 14, 2020

Published: February 17, 2020

Copyright (C) 2020 by author(s) and Scientific Research Publishing Inc. This work is licensed under the Creative Commons Attribution International License (CC BY 4.0).

http://creativecommons.org/licenses/by/4.0/

Open Access

\begin{abstract}
Background: There has been much debate and inquiry surrounding the nature of the increase in prevalence of autism spectrum disorder (ASD). There are many environmental risk factors that have been postulated to be associated with the development of ASD. Cosmetic products are widely used in daily life. The aim of this study was to clarify whether maternal cosmetics usage is a risk factor of ASD. Patients and Methods: The present work was a cross sectional case-control study. Fifty eight mothers with children, who have been diagnosed with ASD by meeting the DMS- 5 criteria, were compared with 49 mothers with neurotypical children. The mothers were asked to complete a short questionnaire comprised their use of cosmetics outside of pregnancy and changes in use during pregnancy. Results: No statistically significant difference was found between cases and controls as regard the overall usage of cosmetics. Indoors usage of makeup was significantly higher among mothers with autistic children than mothers of controls $(\mathrm{p}=0.36)$. The duration of cosmetics usage was significantly higher among the mothers of controls than mothers with autistic children $(\mathrm{p}=0.011)$. Eyes and lips makeup were the most frequent of makeup type among mothers with autistic children and controls while hair protein or keratin were the least frequent of makeup type among both groups. The number of women who reported the usage of lips makeup was significantly higher among the mothers of controls than those with autistic children $(\mathrm{p}=0.024)$. The number of mothers with autistic children who reported "no change" as regard the usage pattern during pregnancy was significantly higher than those of the controls $(p=0.042)$. Conclusions: According to our results, cosmetics could not be considered as a
\end{abstract}


risk factor for ASD. Further understanding of this issue requires future studies with different designs.

\section{Keywords}

Autism, ASD, Cosmetics, Personal Care Products, Endocrine Disruptors

\section{Introduction}

Difficulties with social communication and restricted, repetitive patterns of behavior, interest, or activities are the main features of autism spectrum disorder (ASD) [1]. There have been a lot of discussions and requests encompassing the idea of the expansion in commonness of ASD. In a study done in a western country, autism spectrum disorders were estimated to affect 1 in 68 (or 147 in 10,000 , reported in 2010 for birth year 2002), which is $30 \%$ higher than the previous (2008) estimate of 1 in 88 [2]. Several factors are thought to share a significant role in the etiology of ASD, i.e. socio economic status, hereditary, epigenetic factors, environmental factors and close gene/environment relationships [3]. While ASD has proven highly heritable, there is more to the story than genetics alone can explain [4]. Various hereditary disorders are known to have critical relationship with autism [5], yet these are responsible for a minority of cases [4]. And keeping in mind that the accurate extents from various studies differ, monozygotic twin concordance rates of autism and associated conditions reliably sum to less than $100 \%$, which emphatically propose a role for environmental factors [6]. ASD was once viewed as a childhood condition, endeavors for early discovery prompted the acknowledgment that it may begin at a much earlier stage, specifically fetal life [7].

There are numerous environmental risk factors that have been hypothesized to be related to the development of ASD including pre-eclampsia, maternal hypertension, autoimmune disease, diabetes mellitus, and infection during pregnancy [8]. Maternal treatment with pharmaceutical agents, for example, the thalidomide, the valproic acid, and certain antidepressants, particularly during first trimester of pregnancy, has been related with an expanded risk of ASD in the offspring [9] [10]. A detrimental consequence can occur in the developmental processes, particularly for genetically susceptible individuals, once exposed to different toxicants, including polychlorinated biphenyls, pesticides, and polybrominated diphenyl ethers [4]. Moreover, several neurotoxic compounds are suspected to intervene with neurotransmitter systems also implicated in ASD [11].

Cosmetic items have long been utilized by the individuals around the globe so as to improve personal appearance and maintain personal hygiene and safety. Varieties of beauty care products with discrete capacities are at present available [12]. The European Union Cosmetics Directive defines a cosmetic product or personal care product (PCP) as "any substance or mixture intended to be placed 
in contact with the external parts of the human body (epidermis, hair system, nails, lips and external genital organs) or with the teeth and the mucous membranes of the oral cavity with a view exclusively or mainly to cleaning them, perfuming them, changing their appearance, protecting them, keeping them in good condition or correcting body odors" [13]. Cosmetic products are immensely utilized in day by day life. They contain different synthetic substances, for example, as phthalates and other plasticizers, bisphenol A, parabens, benzophenones (ultraviolet filters), polycyclic musks, triclosan (antimicrobials), dioxane, organic solvents, pigments, formaldehyde, and heavy metals that serve as active ingredients, solvents, preservatives and additives to improve their adequacy and increment the term of their effect [14] [15] [16] [17]. These agents may be potential endocrine disruptors [18]. An endocrine-disrupting chemical (EDC) is defined by the World Health Organization as "an exogenous substance or mixture that alters function(s) of the endocrine system and consequently causes adverse health effects in an intact organism, or its progeny, or (sub)populations" [19]. A variety of autistic features may result from prenatal exposures to EDCs, via alterations in gene expression, prompting altered hormonal signaling pathways [20]. Over recent decades, cosmetics and many other chemicals have been suspected to be endocrine disruptors [21].

The aim of this study was to clarify whether maternal cosmetics usage is a risk factor of ASD.

\section{Patients and Methods}

The present work was a cross sectional case-control study, carried out during the period from December 2017 to November 2018. Participants were comprised of mothers with children between the age of 2 and 12 who have been diagnosed with ASD by meeting the DMS- 5 criteria [22]. Mothers of children with known neurogenetic conditions (e.g., tuberous sclerosis, neurofibromatosis, fragile $\mathrm{X}$ syndrome, Down syndrome) were excluded. They were recruited from the Neuropediatric Clinic, Pediatric Department, Sohag University Hospital. Age-matched mothers with neurotypical children served as controls. They were recruited from the General pediatric Clinic, Pediatric Department, Sohag University Hospital. The children of the control group were evaluated to exclude the presence of any neurocognetive disorders. The study was approved by the Medical Research Ethical Committee of Sohag Faculty of Medicine. Consents were obtained from participants.

All participants were subjected to the following:

1) Mothers

Detailed history taking with special emphasis on consanguinity, complications during the index pregnancy or delivery, the age of the mother during the index pregnancy, the presence of chronic illness as hypertension and Diabetes mellitus (DM), medications during pregnancy (e.g. antiepileptic or anti-thyroid drugs).

2) Children 
Detailed history taking with special emphasis on perinatal problems and postnatal course especially occurrence of neonatal hypoxia and jaundice, age of walking unassisted, first spoken words, the presence of any other neurological diseases and family history of autism or other neurological diseases.

Through clinical examination, with laying stress on, neurological examination.

Confirmation of diagnosis using DSM 5 criteria of autism, i.e., deficit in social-emotional reciprocity, deficits in non verbal communicative behaviors, deficits in developing, maintaining and understanding relationships, and restricted stereotyped interest or activity.

Assessment of severity of autistic symptoms using childhood autism rating scale (CARS) [23].

The mothers were informed of the aim of the study and what it would entail, they were asked to complete a short questionnaire (Table 1). The questionnaire comprised their use of cosmetics outside of pregnancy and changes in use during pregnancy.

\section{Statistics Analysis}

The statistical analysis was performed using the Statistical Package for the Social Sciences (SPSS 20.0, SPSS Inc., Chicago, IL, USA) For Windows. Descriptive statistics were done to investigate the general characteristics of the patients. The case and control groups were compared using the Student's $t$ test for the continuous variables and the chi-square test for the categorical variables. Pearson's correlation was used to detect possible risk factors of autism. All the results were

Table 1. Questionnaire for cosmetics usage.

- Do you use makeup?

o Yes 0 No

- What kind of makeup?
o Makeup for face
o Products for eyes
o Products for lips
o Nail polish
o Hair dyes
o Protein or keratin for hair

- How long have you been using these products?

o

- How much time do you put these products?
o The whole day
o Most of the day
o Few hours
o Rarely

- In what place do you put these products?
0 Indoors
o Outdoors
o Indoors and outdoors

- What determines your choice when buying makeup?
0 The ingredients
o The price
o Odor
o Original brand
o Friend tip
o Medical advice

- Usage during pregnancy.
o Usage increases
o Usage decreases
o Change types
o No change 
considered significant when $\mathrm{p}<0.05$.

\section{Results}

Table 2 shows demographic, prenatal, perinatal and postnatal data of cases and controls. No significant differences were found between mothers of autistic children and those of the control children as regard the age or the educational level. Family history of autism was significantly higher among patients with ASD $(\mathrm{p}$-Value $=0.038)$. Delayed language was significantly higher among patients with ASD ( $\mathrm{p}$-Value $=0.0001)$. Moreover, delayed walking was significantly higher among patients with ASD ( $\mathrm{p}$-Value $=0.0001$ ). As regard drug exposure during the index pregnancy; among mothers with autistic children, two exposed to anticoagulant therapy, two exposed to antidiabetic treatment, one exposed to antiasthmatic treatment, one exposed to antihypertensives, one exposed to tocolytic therapy, and one to iron therapy. On the other hand, among mothers of the control children, one exposed to anticoagulant therapy, one exposed to antidiabetic treatment, one exposed to antiasthmatic treatment, one exposed to antihypertensives, and two to iron therapy. Figure 1 reveals the frequency of different medical conditions among mothers of cases and controls during the index pregnancy.

Figure 2 reveals Prenatal and postnatal insults of patients and controls. Twenty three of our patients (39.7\%) had mild to moderate degree of autism with CARS (30 - 36.5), and 35 patients (60.3\%) had severe autism with CARS ( $\geq 37)$. Table 3 shows the pattern of cosmetics usage of cases and controls. The overall usage of cosmetics among mothers of the controls was higher than those with autistic children, however the difference was statistically non significant. Indoors usage of makeup was significantly higher among mothers with autistic children than mothers of controls, while outdoors and mixed indoors and outdoors usage was significantly higher among the mothers of controls than those with autistic children $(p=0.036)$. Eyes and Lips makeup were the most frequent of makeup type among mothers with autistic children and controls while hair protein or keratin was the least frequent of makeup type among both groups.

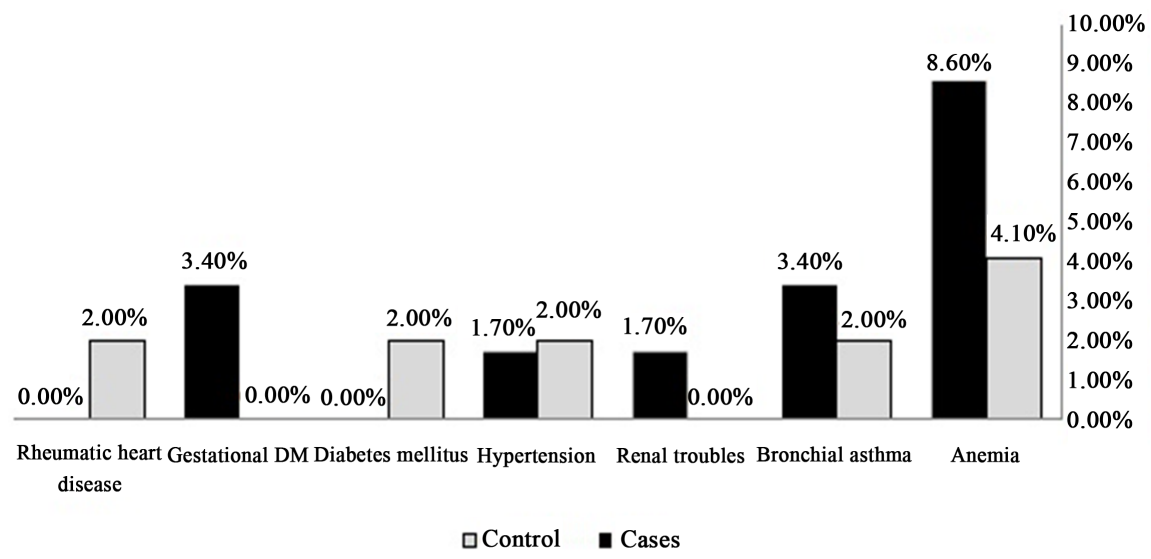

Figure 1. Medical illnesses among mothers of cases and controls during the index pregnancy. 


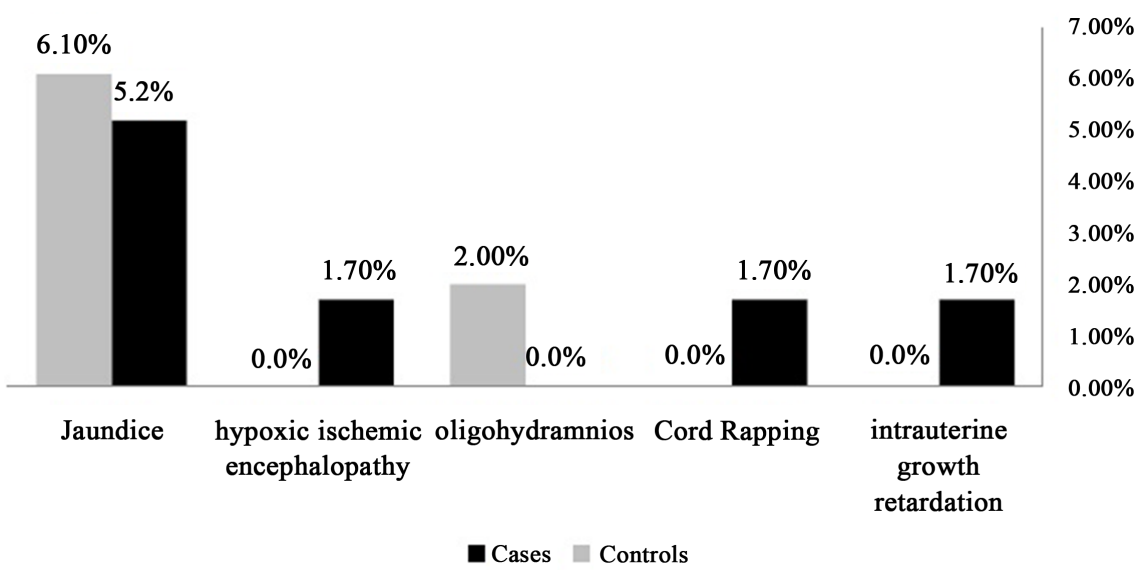

Figure 2. Prenatal and postnatal insults of patients and controls.

Table 2. Demographic, prenatal, perinatal and postnatal data of cases and controls.

\begin{tabular}{|c|c|c|c|}
\hline & $\begin{array}{c}\text { Cases } \\
(\mathrm{N}=58)\end{array}$ & $\begin{array}{l}\text { Control } \\
(\mathrm{N}=49)\end{array}$ & P-value \\
\hline Mother's age (Mean \pm SD) & $30.2 \pm 5.3$ & $29.8 \pm 5.4$ & 0.71 \\
\hline Mother's age during pregnancy (Mean $\pm S D$ ) & $26.7 \pm 5.2$ & $25.2 \pm 4.7$ & 0.114 \\
\hline \multicolumn{4}{|l|}{ Maternal educational level } \\
\hline Illiterate, no. (\%) & $9(15.5)$ & $10(20.4)$ & 0.313 \\
\hline Elementary School, no. (\%) & $6(10.3)$ & $7(14.3)$ & \\
\hline Middle school, no. (\%) & $10(17.2)$ & $13(26.5)$ & \\
\hline High School, no. (\%) & $33(56.9)$ & $19(38.8)$ & \\
\hline Family history of Autism, no. (\%) & $15(25.9)$ & $5(10.2)$ & 0.038 \\
\hline Family history epilepsy, no. (\%) & $1(1.7)$ & $1(2.0)$ & 0.904 \\
\hline Family history ADHD, no. (\%) & $1(1.7)$ & $0(0.0)$ & 0.356 \\
\hline Parents consanguinity, no. (\%) & $24(41.4)$ & $24(49.0)$ & 0.431 \\
\hline Age of child (Mean \pm SD) & $3.3 \pm 1.8$ & $4.8 \pm 2.4$ & 0.001 \\
\hline \multicolumn{4}{|l|}{ Sex of child } \\
\hline Male, no. (\%) & $43(74.1)$ & $27(55.1)$ & 0.039 \\
\hline Female, no. (\%) & $15(25.9)$ & $22(44.9)$ & \\
\hline Delayed language, no. (\%) & $58(100)$ & $0(0)$ & 0.0001 \\
\hline Delayed walking, no. (\%) & $19(32.7)$ & $0(0)$ & 0.0001 \\
\hline Maternal drug intake during pregnancy & $8(13.7)$ & $6(12.2)$ & 0.942 \\
\hline Maternal medical illness during pregnancy & $11(19.0)$ & $6(12.2)$ & 0.343 \\
\hline Fetal prenatal complications & $2(3.4)$ & $1(2.0)$ & 0.66 \\
\hline Fetal Postnatal complications & $4(6.8)$ & $3(6.1)$ & 0.87 \\
\hline
\end{tabular}


Table 3. Pattern of cosmetics usage of cases and controls.

\begin{tabular}{|c|c|c|c|}
\hline & Cases $(\mathrm{N}=58)$ & Control $(\mathrm{N}=49)$ & P-value \\
\hline Overall usage of cosmetics, no. (\%) & $39(67.2)$ & $41(83.7)$ & 0.051 \\
\hline \multicolumn{4}{|l|}{ Place of usage } \\
\hline Indoors, no. (\%) & $25(43.1)$ & $15(30.6)$ & 0.036 \\
\hline Outdoors, no. (\%) & $4(6.9)$ & $8(16.3)$ & \\
\hline Indoors and Outdoors, no. (\%) & $10(17.2)$ & $17(34.7)$ & \\
\hline \multicolumn{4}{|l|}{ Type of makeup } \\
\hline Face makeup, no. (\%) & $28(48.3)$ & $28(57.1)$ & 0.360 \\
\hline Eye makeup, no. (\%) & $29(50.0)$ & $32(65.3)$ & 0.111 \\
\hline Lips makeup, no. (\%) & $29(50.0)$ & $35(71.4)$ & 0.024 \\
\hline Nail polish, no. (\%) & $12(20.7)$ & $18(36.7)$ & 0.066 \\
\hline Hair dyes, no. (\%) & $11(19.0)$ & $16(32.7)$ & 0.104 \\
\hline Hair protein or keratin, no. (\%) & $2(3.5)$ & $3(6.1)$ & 0.527 \\
\hline $\begin{array}{l}\text { Duration of cosmetics usage (in years), } \\
\text { (Mean } \pm \text { SD) }\end{array}$ & $4.57 \pm 4.7$ & $7.22 \pm 5.5$ & 0.011 \\
\hline \multicolumn{4}{|l|}{ Time pattern of daily usage } \\
\hline No usage, no. (\%) & $19(32.7)$ & $9(18.3)$ & 0.151 \\
\hline Rarely, no. (\%) & $8(13.7)$ & $9(18.3)$ & \\
\hline Few hours, no. $(\%)$ & $24(41.3)$ & $25(51.02)$ & \\
\hline Most of the day, no. (\%) & $6(10.3)$ & $2(4.08)$ & \\
\hline All of the day, no. (\%) & $1(1.7)$ & $4(8.16)$ & \\
\hline \multicolumn{4}{|l|}{ How to choose make up products } \\
\hline Brand name (Quality) & $7(12.1)$ & $8(16.3)$ & 0.244 \\
\hline Odour & $1(1.7)$ & $5(10.2)$ & \\
\hline Price & $17(29.3)$ & $13(26.5)$ & \\
\hline Contents & $0(0.0)$ & $2(4.1)$ & \\
\hline Friend advice & $14(24.1)$ & $11(22.4)$ & \\
\hline Medical Advice & $1(1.7)$ & $1(2.0)$ & \\
\hline \multicolumn{4}{|l|}{ Usage during pregnancy } \\
\hline Decreased & $20(40.8)$ & $17(29.3)$ & 0.042 \\
\hline Increased & $0(0.0)$ & $3(5.2)$ & \\
\hline No change & $19(38.8)$ & $14(24.1)$ & \\
\hline Not used during pregnancy & $1(2.0)$ & $6(10.3)$ & \\
\hline
\end{tabular}

The number of women who reported the usage of Lips makeup was significantly higher among the mothers of controls than those with autistic children ( $p$ $=0.024)$. The duration of cosmetics usage was significantly higher among the mothers of controls than mothers with autistic children $(\mathrm{p}=0.011)$. As regard 
the time pattern of daily usage no statistically significant difference was found between both groups. "Few hours per day" was the most frequent time pattern of daily usage among mothers with autistic children and controls. "All of the day" was the least frequent time pattern of daily usage among mothers with autistic children, while "most of the day" was the least frequent pattern among mothers of controls. Results of the study revealed that the most frequent reason for selecting cosmetics among mothers with autistic children and controls is product's price and the least frequent reason for selecting was the product's contents with no statistically significant difference between both groups. The number of mothers with autistic children who reported "no change" as regard the usage pattern during pregnancy were significantly higher than those of the controls $(\mathrm{p}$ $=0.042$ ).

\section{Discussion}

As a pilot study, the authors, in the present work, attempted to answer important questions about feasibility and methodological issues regarding a future large scale study, to see if cosmetics use is a risk factor for autism? Hallmayer and colleagues, in their study, found that genetics are the attributable causes in only $38 \%$ of ASD cases [6]. This finding, when added to the rapidly increasing prevalence of ASD, has prompted perceive that environmental factors may play a noteworthy role in the etiology and pathogenesis of ASD [24] [25] [26]. Endocrine disruptors merit thought as candidate risk factors for ASDs as a result of their capability to change hormonal axis functions that assume a significant role in neurodevelopment [27]. Women, during pregnancy, are especially helpless against the potential dangers of the endocrine disruptors contained in cosmetics [18]. Our results revealed modest and imprecise differences between cases and controls. However, statistical significance is not the main concern in pilot studies [28]. We found that, family history of autism was significantly higher among autistic children. In line with this finding, La Salle and colleagues reported that, while there is a strong genetic basis for ASD in some individual cases, the genetics of ASD is decidedly complex, and many cases of ASD are likely to involve complex interactions between genetic and environmental risk factors [25]. Our results pointed to the higher risk of autism in boys than girls. This finding was consistent with that reported by Shu and colleagues who said that autism is more than twice as common in boys as girls [29]. Also an Egyptian study reported that boys are in greater risk than girls as regard the development of ASD [30].

According to our results, cosmetics could not be considered as a risk factor for ASD. However, valuable findings could be extracted from our work for future consideration.

Socioeconomic factors significantly influence the utilization pattern of cosmetic products [31]. The authors stated in a previous study that the higher the socio-economic status, the greater the use of makeup [32]. Sohag is considered 
as one of the poorest governorates in Egypt [33]. In line with these studies, we found that, "few hours" is the most frequent time pattern of makeup usage among our subjects with no significant difference between both groups. These findings could affect the generalizability of our results and create difficulties in ascertaining causality. Similar to other conservative eastern societies [32] [34], indoors usage of cosmetics was the most frequent place pattern among our subjects, moreover, this pattern was significantly higher among mothers with autistic children than those of the controls. This place pattern may be associated with heavier cosmetics usage and more health implications.

Lips makeup, together with Eyes makeup, were the most frequent makeup type among mothers with autistic children and controls. According to a report published in 2007 by the Campaign for Safe Cosmetics, 61 percent of lipsticks contained lead, with levels ranging up to 0.65 parts per million [35]. In 2009 and 2011, reports were published by the Food and Drug Administration (FDA) about the levels of lead found in lipsticks [36]. Another study once again, turns attention to metals in lip products, this time investigating levels of lead as well as of other metals. All of the studied items (32 lip products) contained manganese, titanium, and aluminum, with the last two metals showing up at the highest concentrations. Seventy five percent of the products contained noticeable measures of lead, and in almost a large portion of the samples, lead levels were higher than the FDA standard of $0.1 \mathrm{ppm}$ for lead in candy. As indicated by the authors, neither price nor kind of item (lipstick versus lip gloss) influenced the metal concentrations [37]. Accordingly, lip products may be a hazardous source of non healthy dose of different metals that may play an important role in the neurodevelopment of the fetus if used during pregnancy. Being significantly higher among mothers of controls than those of autistic children can be explained in many ways; firstly, the small sample size of our study; secondly, the cross section design of the study in which, the daily amount applied, and the brand type with its gradients were not detected; lastly, the epigenetic effects, rather than the pure environmental impact, of these products may be accused.

Eyes makeup was the second most commonly used makeup type among our population, with no significant difference between both groups. Regarding this issue, De Caluwé reported that, use of kohl as an eye cosmetic is very common in North Africa (Egypt, Morocco, Algeria). This practice has now become widespread in European nations and North America. In a great number of kohls accessible on the free market, lead sulfide is the principle component and the very high lead concentration is a risk, especially for women and children [38].

The third most common makeup type among our population, also with no significant difference between both groups was face makeup. Iwegbue and colleagues reported that, the mean concentrations of $\mathrm{Cd}$ in facial powders reached the Canadian Authority's limit of $3 \mu \mathrm{g} \cdot \mathrm{g}^{-1}$ for the total allowable Cd as cosmetic impurity [39]. The use of Cd in beauty products is due to its ability to produce various colors in combination with other elements and has been used in many 
industries as a color pigment [40].

Moderate level of usage was reported by our subjects as regard nail polish and hair dyes, with no significant difference between both groups. Mendelsohn and colleagues reported that, most nail polish samples (8 out of 10) contained detectable levels of triphenyl phosphate (an organophosphorus compound) [41]. Triphenyl phosphate exposure has been related to reproductive and developmental toxicity, neurotoxicity, metabolic disturbance, endocrine effects and genotoxicity in several toxicological studies [42] [43].

The duration of cosmetics usage was significantly longer among mothers of control children. This finding could prove the lack of a relationship between cosmetics and risk of ASD.

We found that, the number of women who reported "no change" as regard the usage pattern during pregnancy were significantly higher among mothers of autistic children than those of the control. Barrett and colleagues showed that, because of their belief that environmental chemicals are dangerous, some pregnant women behave in a healthy manner, particularly with regard to food, and often choose environmentally friendly PCPs [44]. Marie and colleagues reported that, nearly half of the women (45\%) in their study felt there was no danger of makeup being used during pregnancy. It is now recognized, however, that these products contain numerous potentially harmful chemicals including antimicrobials, plasticizers, parabens, bisphenol A, syntheticdyes, benzophenones, dioxane, heavy metals and formaldehyde [14] [15] [16] [17].

The current study has certain limitations. Firstly, its cross-sectional nature creates difficulties in ascertaining causality. Secondly, the study was restricted to cosmetics, (not all personal care products) like soaps, deodorant, antiperspirants, body lotions, creams, oils, toothpaste and shampoo.

Future studies should be long term cohorts with daily diaries describing personal care products usage during index pregnancy and post-partum period. Details about the brand and manufacturer of the product, the amount of product used per application, the contents in each product and their levels in the blood should be discussed. Moreover future studies should be multicenter studies including localities with high socioeconomic states known with their heavy usage of cosmetics.

\section{Conflicts of Interest}

The authors declare no conflicts of interest regarding the publication of this paper.

\section{References}

[1] Sanchack, K.E. and Thomas, C.A. (2016) Autism Spectrum Disorder: Primary Care Principles. American Family Physician, 94, 972-979.

[2] McCarthy, M. (2014) Autism Diagnoses in the US Rise by 30\%, CDC Reports. BMJ, 348, g2520. https://doi.org/10.1136/bmj.g2520

[3] Geetha, B., Sukumar, C., Dhivyadeepa, E., Reddy, J.K. and Balachandar, V. (2018) 
Autism in India: A Case-Control Study to Understand the Association between Socio-Economic and Environmental Risk Factors. Acta Neurologica Belgica, 119, 393-401. https://doi.org/10.1007/s13760-018-01057-4

[4] Matelski, L. and Van de Water, J. (2016) Risk Factors in Autism: Thinking outside the Brain. Journal of Autoimmunity, 67, 1-7.

https://doi.org/10.1016/j.jaut.2015.11.003

[5] Zafeiriou, D.I., Ververi, A., Dafoulis, V., Kalyva, E. and Vargiami, E. (2013) Autism Spectrum Disorders: The Quest for Genetic Syndromes. American Journal of Medical Genetics Part B: Neuropsychiatric Genetics, 162, 327-366. https://doi.org/10.1002/ajmg.b.32152

[6] Hallmayer, J., Cleveland, S., Torres, A., Phillips, J., Cohen, B., Torigoe, T., et al. (2011) Genetic Heritability and Shared Environmental Factors among Twin Pairs with Autism. Archives of General Psychiatry, 68, 1095-1102. https://doi.org/10.1001/archgenpsychiatry.2011.76

[7] Connors, S.L., Levitt, P., Matthews, S.G., Slotkin, T.A., Johnston, M.V., Kinney, H.C., et al. (2008) Fetal Mechanisms in Neurodevelopmental Disorders. Pediatric Neurology, 38, 163-176. https://doi.org/10.1016/j.pediatrneurol.2007.10.009

[8] Moussa, H.N., Srikrishnan, A., Blackwell, S.C., Dash, P. and Sibai, B.M. (2016) Fetal Origins of Autism Spectrum Disorders: The Non-Associated Maternal Factors. Future Science $O A, 2$, FSO114. https://doi.org/10.4155/fsoa-2015-0001

[9] Croen, L.A., Grether, J.K., Yoshida, C.K., Odouli, R. and Hendrick, V. (2011) Antidepressant Use during Pregnancy and Childhood Autism Spectrum Disorders. Archives of General Psychiatry, 68, 1104-1112. https://doi.org/10.1001/archgenpsychiatry.2011.73

[10] Christensen, J., Gronborg, T.K., Sorensen, M.J., Schendel, D., Parner, E.T., Pedersen, L.H., et al. (2013) Prenatal Valproate Exposure and Risk of Autism Spectrum Disorders and Childhood Autism. JAMA, 309, 1696-1703. https://doi.org/10.1001/jama.2013.2270

[11] Quaak, I., Brouns, M.R. and Van de Bor, M. (2013) The Dynamics of Autism Spectrum Disorders: How Neurotoxic Compounds and Neurotransmitters Interact. International Journal of Environmental Research and Public Health, 10, 3384-3408. https://doi.org/10.3390/ijerph10083384

[12] Noor, R., Zerin, N., Das, K.K. and Nitu, L.N. (2015) Safe Usage of Cosmetics in Bangladesh: A Quality Perspective Based on Microbiological Attributes. Journal of Biological Research (Thessalon), 22, 10. https://doi.org/10.1186/s40709-015-0033-4

[13] Union E. Regulation (EC) No 1223/2009 of the European Parliament and of the Council of 30 November 2009 on Cosmetic Products 2009. https://eur-lex.europa.eu/legal-content/EN/ALL/?uri=CELEX\%3A32009R1223

[14] Juhasz, M.L. and Marmur, E.S. (2014) A Review of Selected Chemical Additives in Cosmetic Products. Dermatologic Therapy, 27, 317-322. https://doi.org/10.1111/dth.12146

[15] Witorsch, R.J. and Thomas, J.A. (2010) Personal Care Products and Endocrine Disruption: A Critical Review of the Literature. Critical Reviews in Toxicology, 40, 1-30. https://doi.org/10.3109/10408444.2010.515563

[16] Dodson, R.E., Nishioka, M., Standley, L.J., Perovich, L.J., Brody, J.G. and Rudel, R.A. (2012) Endocrine Disruptors and Asthma-Associated Chemicals in Consumer Products. Environmental Health Perspectives, 120, 935-943. https://doi.org/10.1289/ehp.1104052

[17] Bocca, B., Pino, A., Alimonti, A. and Forte, G. (2014) Toxic Metals Contained in 
Cosmetics: A Status Report. Regulatory Toxicology and Pharmacology, 68, 447-467. https://doi.org/10.1016/j.yrtph.2014.02.003

[18] Marie, C., Cabut, S., Vendittelli, F. and Sauvant-Rochat, M.P. (2016) Changes in Cosmetics Use during Pregnancy and Risk Perception by Women. International Journal of Environmental Research and Public Health, 13, 383. https://doi.org/10.3390/ijerph13040383

[19] Safety IPoC (2002) Global Assessment on the State of the Science of Endocrine Disruptors. World Health Organization, Geneva. https://apps.who.int/iris/handle/10665/67357

[20] Mari-Bauset, S., Donat-Vargas, C., Llopis-Gonzalez, A., Mari-Sanchis, A., Peraita-Costa, I., Llopis-Morales, J., et al. (2018) Endocrine Disruptors and Autism Spectrum Disorder in Pregnancy: A Review and Evaluation of the Quality of the Epidemiological Evidence. Children (Basel, Switzerland), 5, 157.

https://doi.org/10.3390/children5120157

[21] Haraux, E., Braun, K., Buisson, P., Stephan-Blanchard, E., Devauchelle, C., Ricard, J., et al. (2016) Maternal Exposure to Domestic Hair Cosmetics and Occupational Endocrine Disruptors Is Associated with a Higher Risk of Hypospadias in the Offspring. International Journal of Environmental Research and Public Health, 14, 27. https://doi.org/10.3390/ijerph14010027

[22] American Psychiatric Association (2013) Diagnostic and Statistical Manual of Mental Disorders. 5th Edition, Washington DC.

[23] Schopler, E., Reichler, R.J. and Renner, B.R. (1986) The Childhood Autism Rating Scale (CARS): For Diagnostic Screening and Classification of Autism. Irvington, New York, 63 p.

[24] Hu, V.W. (2013) From Genes to Environment: Using Integrative Genomics to Build a "Systems-Level" Understanding of Autism Spectrum Disorders. Child Development, 84, 89-103. https://doi.org/10.1111/j.1467-8624.2012.01759.x

[25] LaSalle, J.M. (2013) Epigenomic Strategies at the Interface of Genetic and Environmental Risk Factors for Autism. Journal of Human Genetics, 58, 396-401.

https://doi.org/10.1038/jhg.2013.49

[26] Ronald, A., Pennell, C.E. and Whitehouse, A.J. (2010) Prenatal Maternal Stress Associated with ADHD and Autistic Traits in Early Childhood. Frontiers in Psychology, 1, 223. https://doi.org/10.3389/fpsyg.2010.00223

[27] Braun, J.M., Kalkbrenner, A.E., Just, A.C., Yolton, K., Calafat, A.M., Sjodin, A., et al. (2014) Gestational Exposure to Endocrine-Disrupting Chemicals and Reciprocal Social, Repetitive, and Stereotypic Behaviors in 4- and 5-Year-Old Children: The HOME Study. Environmental Health Perspectives, 122, 513-520. https://doi.org/10.1289/ehp.1307261

[28] Thabane, L., Ma, J., Chu, R., Cheng, J., Ismaila, A., Rios, L.P., et al. (2010) A Tutorial on Pilot Studies: The What, Why and How. BMC Medical Research Methodolo$g y, 10,1$. https://doi.org/10.1186/1471-2288-10-1

[29] Shu, B.C., Lung, F.W. and Chang, Y.Y. (2000) The Mental Health in Mothers with Autistic Children: A Case-Control Study in Southern Taiwan. The Kaohsiung Journal of Medical Sciences, 16, 308-314.

[30] El-Baz, F., Ismael, N.A. and El-Din, S.M.N. (2011) Risk Factors for Autism: An Egyptian Study. Egyptian Journal of Medical Human Genetics, 12, 31-38. https://doi.org/10.1016/j.ejmhg.2011.02.011

[31] Park, G.H., Nam, C., Hong, S., Park, B., Kim, H., Lee, T., et al. (2018) Socioeconomic Factors Influencing Cosmetic Usage Patterns. Journal of Exposure Science \& 
Environmental Epidemiology, 28, 242-250. https://doi.org/10.1038/jes.2017.20

[32] Tarrahi, M.-J., Bahmani, M., Mohadesi, H., Hajigholizadeh, G.H. and Nazari, E. (2016) Studying the Status of Cosmetics Consumption among Women and Girls in Urmia University of Medical Sciences, Northwest of Iran. Austin Journal of Neurological Disorders \& Epilepsy, 3, 1021.

[33] Benova, L., Campbell, O.M., Sholkamy, H. and Ploubidis, G.B. (2014) Socio-Economic Factors Associated with Maternal Health-Seeking Behaviours among Women from Poor Households in Rural Egypt. International Journal for Equity in Health, 13, 111. https://doi.org/10.1186/s12939-014-0111-5

[34] Alanzi, M.E., Alghamdi, R.A., Alsharif, O.M., Alghamdi, K.S. and El Sayed, S.M. (2018) Health Knowledge, Cosmetic Interests, Attitude, and the Need for Health Education Regarding the Use of Topical Bleaching Agents among Women in West Saudi Arabia: A Cross-Sectional Study. Journal of Cosmetic Science, 69, 101-120.

[35] The Campaign for Safe Cosmetics (2007) A Poison Kiss: The Problem of Lead in Lipstick. Safe Cosmetics Action Network. http://www.safecosmetics.org/get-the-facts/regulations/us-laws/lead-in-lipstick

[36] Brown, V.J. (2013) Metals in Lip Products: A Cause for Concern? Environmental Health Perspectives, 121, A196. https://doi.org/10.1289/ehp.121-a196

[37] Liu, S., Hammond, S.K. and Rojas-Cheatham, A. (2013) Concentrations and Potential Health Risks of Metals in Lip Products. Environmental Health Perspectives, 121, 705-710. https://doi.org/10.1289/ehp.1205518

[38] De Caluwe, J.P. (2009) Lead Poisoning Caused by Prolonged Use of Kohl, an Underestimated Cause in French-Speaking Countries. Journal Francais d ophtalmologie, 32, 459-463. https://doi.org/10.1016/j.jfo.2009.06.005

[39] Iwegbue, C.M.A., Bassey, F.I., Obi, G., Tesi, G.O. and Martincigh, B.S. (2016) Concentrations and Exposure Risks of Some Metals in Facial Cosmetics in Nigeria. Toxicology Reports, 3, 464-472. https://doi.org/10.1016/j.toxrep.2016.04.004

[40] Godt, J., Scheidig, F., Grosse-Siestrup, C., Esche, V., Brandenburg, P., Reich, A., et al. (2006) The Toxicity of Cadmium and Resulting Hazards for Human Health. Journal of Occupational Medicine and Toxicology (London, England), 1, 22. https://doi.org/10.1186/1745-6673-1-22

[41] Mendelsohn, E., Hagopian, A., Hoffman, K., Butt, C.M., Lorenzo, A., Congleton, J., et al. (2016) Nail Polish as a Source of Exposure to Triphenyl Phosphate. Environment International, 86, 45-51. https://doi.org/10.1016/j.envint.2015.10.005

[42] Du, Z., Zhang, Y., Wang, G., Peng, J., Wang, Z. and Gao, S. (2016) TPhP Exposure Disturbs Carbohydrate Metabolism, Lipid Metabolism, and the DNA Damage Repair System in Zebrafish Liver. Scientific Reports, 6, Article No. 21827. https://doi.org/10.1038/srep21827

[43] Zhang, Q., Ji, C., Yin, X., Yan, L., Lu, M. and Zhao, M. (2016) Thyroid Hormone-Disrupting Activity and Ecological Risk Assessment of Phosphorus-Containing Flame Retardants by in Vitro, in Vivo and in Silico Approaches. Environmental Pollution (Barking, Essex: 1987), 210, 27-33. https://doi.org/10.1016/j.envpol.2015.11.051

[44] Barrett, E.S., Sathyanarayana, S., Janssen, S., Redmon, J.B., Nguyen, R.H., Kobrosly, R., et al. (2014) Environmental Health Attitudes and Behaviors: Findings from a Large Pregnancy Cohort Study. European Journal of Obstetrics, Gynecology, and Reproductive Biology, 176, 119-125. https://doi.org/10.1016/j.ejogrb.2014.02.029 